10.1590/S1414-40772018000300013

Este é um artigo publicado em acesso aberto sob uma licença Creative Commons

https://creativecommons.org/licenses/by-nc/4.0/

\title{
Perfil dos estudantes participantes do Programa Andifes de Mobilidade Acadêmica
}

\author{
Raquel Leite Braz ${ }^{1}$ \\ Maria do Carmo de Lacerda Peixoto ${ }^{2}$
}

Resumo: A mobilidade acadêmica constitui-se em um elemento importante para o ensino superior desde seus primórdios. Ao longo do processo de globalização, as políticas educacionais para internacionalização da educação foram intensificadas, ampliando a migração acadêmica temporária dos estudantes universitários. Na educação superior brasileira, constituída por um sistema complexo e diversificado de instituições públicas e privadas com diferentes tipos de cursos e programas, há as modalidades de mobilidade acadêmica internacional e nacional. Em 2003, foi criado pela Associação Nacional dos Dirigentes das Instituições Federais de Ensino Superior (Andifes) um programa de mobilidade estudantil a ser realizado exclusivamente no território brasileiro. O Programa Andifes de Mobilidade Acadêmica (PAMA) é realizado por meio de convênio firmado entre a Associação e 63 Instituições Federais de Ensino Superior (IFES), estabelecendo uma relação de reciprocidade entre as signatárias para fins de mobilidade dos alunos de graduação, de modo que eles possam cursar os componentes curriculares em instituição federal diversa daquela em que estão regularmente matriculados. Nesta pesquisa, buscou-se identificar o perfil sociodemográfico dos estudantes participantes do Programa e traçar algumas considerações sobre as trajetórias escolares dos mesmos. A metodologia compreendeu a realização de pesquisa documental, entrevistas semi-estruturadas, e a aplicação de um questionário virtual. A análise dos dados mostrou que os estudantes participantes do PAMA são majoritariamente brancos, do sexo feminino, com média de idade de 23 anos, provenientes de famílias pouco numerosas, com menos irmãos, de pais com escolaridade de ensino médio, ou de ensino superior, e com faixa de renda de até 10 salários mínimos. Em grande parte, eles são discentes de cursos de graduação diurnos, da área de Ciências Sociais e Aplicadas, de universidades localizadas na região sudeste e com percursos escolares sem grandes interrupções. Os participantes avaliaram como deficientes a divulgação e as informações sobre o PAMA nas IFES. Neste estudo, chegou-se à conclusão de que, em qualquer escala que se realize, a mobilidade é uma vivência construtiva na formação dos estudantes de ensino superior e que ela deve ser ampliada para alcançar diferentes perfis estudantis.

Palavras-chave: Ensino superior. Instituições federais de ensino superior do Brasil. Mobilidade acadêmica estudantil.

\section{Profile of students participating in the Andifes's Academic Mobility Program}

Abstract: The academic mobility constitutes an important element in higher education since its inception. Throughout the globalization process, education policies for the internationalization of education were intensified, increasing the academic temporary migration of college students. In the Brazilian Higher Education, consisting of a complex and diverse system of public and private institutions with different types of courses and programs, there are modalities for national and international academic mobility. In 2003, he was created by the National Association of Directors of Higher Education Federal Institutions (Andifes) a student mobility program to be held exclusively in Brazilian territory. The Andifes's Academic Mobility Program (PAMA) is performed by means of an agreement between the Association and 63 Federal Institutions of higher education (IFES), establishing a relationship of reciprocity between the signatory for mobility of undergraduate students, so that they can attend the curriculum components in different federal institution that they are regularly enrolled. In this study, we sought to identify the sociodemographic profile of the student participants of the program and draw some considerations on school trajectories of the same. The methodology involved a 
documentary research, the semi-structured interviews, the application of a virtual questionnaire. Data analysis showed that participating students PAMA are mostly white, female, with a mean age of 23 years, from small families, with fewer siblings, parents with a high school education or higher education, and income range of up to 10 minimum wages. Largely, they are students of daytime undergraduate courses, the area of Social and Applied Sciences, universities located in the southeast region and school careers without major interruptions. As the main motivation to participate in the Program, the students pointed out the learning and experiences provided by this experience. The participants evaluated as deficient divulgation and information about PAMA in the IFES. In this study, concluded that, on any scale that takes place, the mobility is a constructive experience in the formation of higher education students and that it should be expanded to reach different student profiles.

Key words: Higher education. Brazilian public institutions of higher education. Academic mobility student. 


\section{Introdução}

A participação dos discentes de graduação em programas de mobilidade acadêmica vem crescendo nos últimos anos. E, entre as causas desse crescimento, estão: a criação de políticas educacionais e de programas institucionais que impulsionaram tal prática entre a comunidade estudantil; e o desenvolvimento dos meios de transporte e comunicação. Essas causas estão aliadas ainda ao contexto da globalização, à interdependência dos lugares e à internacionalização da educação superior. Por conseguinte, a mobilidade acadêmica estudantil ocorre em diversas escalas, do local, entre campus de uma mesma instituição, ao global, entre instituições de países e continentes diferentes.

Em 2003, foi criado pela Associação Nacional dos Dirigentes das Instituições Federais de Ensino Superior (Andifes) o Programa Andifes de Mobilidade Acadêmica (PAMA). Tratase de um programa de mobilidade acadêmica estudantil nacional, isto é, a ser realizado exclusivamente no território brasileiro, ocorrendo durante o ensino da graduação, sendo a participação no programa uma opção do estudante.

O PAMA é realizado por meio de convênio firmado entre a Associação e 63 Instituições Federais de Ensino Superior (IFES), estabelecendo uma relação de reciprocidade entre as signatárias do Programa para fins de mobilidade dos alunos da graduação, de modo que eles possam cursar componentes curriculares em instituição federal diversa daquela em que estão regularmente matriculados.

Este artigo traz um estudo do perfil sociodemográfico dos estudantes participantes do Programa Andifes de Mobilidade Acadêmica. Os dados obtidos são do questionário formulado para esta pesquisa pelas pesquisadoras e aplicado, com o apoio da Andifes, aos discentes participantes do Programa em 2011, 2012 e 2013, os quais obtiveram o benefício da bolsa financiada pelo Banco Santander para o PAMA.

A gestão do Programa é descentralizada, e a Andifes não mantém um cadastro de todos os participantes, apenas daqueles que foram selecionados pelas IFES para receberem as bolsas. Desse modo, a possibilidade de garantir o envio do questionário a participantes de todo território nacional restringiu os sujeitos desta pesquisa aos beneficiários das bolsas do Convênio Andifes/Santander, os quais tinham seus endereços eletrônicos no banco de dados dessa associação.

Assim, mesmo não sendo possível precisar o quantitativo geral de discentes que realizaram a mobilidade acadêmica do PAMA até o presente momento, o recorte utilizado para esta pesquisa garantiu a obtenção de dados de sujeitos de diversas localidades, 
vinculados às diferentes IFES signatárias. Cabe esclarecer que não há um critério único utilizado pelas IFES para seleção dos discentes bolsistas e que a condição socioeconômica não é um parâmetro para essa seleção. Portanto, mesmo que se esteja tratando como sujeitos da pesquisa somente parte dos participantes do PAMA, no caso, os beneficiários de um auxílio financeiro para participação no Programa, observou-se, pelas análises das respostas obtidas, que os respondentes provinham de realidades socioeconômicas distintas.

Os dados obtidos através do questionário foram interpretados à luz das contribuições de estudos do campo da sociologia da educação e, quando possível, foram contrastados com os índices sociodemográficos da sociedade brasileira e com o perfil socioeconômico do estudante de graduação apresentado por Ristoff (2013), o qual analisou os dados do Questionário Socioeconômico (QSE), elaborado pelo Instituto Nacional de Estudos e Pesquisas Educacionais Anísio Teixeira (Inep) e aplicado pelo Exame Nacional de Desempenho dos Estudantes (Enade ${ }^{1}$ ), de 2004 a 2009. Os dados também foram comparados com o Perfil Socioeconômico e Cultural dos Estudantes de Graduação das Universidades Federais Brasileiras, publicado pelo Fonaprace (Fórum Nacional de Pró-Reitores de Assuntos Comunitários e Estudantis), em 2011.

No estudo de Ristoff (2013, p. 21), foi verificado que "o percentual de pretos [na educação superior] começa a se aproximar mais dos percentuais da sociedade, mais pardos frequentam os cursos universitários; e mais pessoas de baixa renda conseguem chegar à educação superior". O autor constatou que o número de matrículas noturnas nas IFES tem aumentado e que mais da metade dos estudantes brasileiros do ensino superior trabalham e estudam. Sendo que a maior parte dos estudantes trabalhadores estava vinculada aos cursos de licenciatura.

Ainda sobre a análise dos dados do Inep, Ristoff (2013) averiguou que, somente em sete cursos, dos quais seis são de licenciatura, e no curso de Serviço Social, os percentuais da renda dos estudantes, na faixa de até três salários mínimos, são superiores a 50\%. Dessa forma, ele conclui que a origem social do educando e a situação socioeconômica das famílias são fatores determinantes na trajetória rumo à educação superior e na escolha do curso de graduação. O número de estudantes oriundos de escolas públicas de ensino médio e de filhos

1 O Enade é um dos procedimentos de avaliação do Sistema Nacional de Avaliação da Educação Superior (Sinaes), instituído pela Lei $\mathrm{n}^{\circ} 10.861$, de 2004, e realizado pelo Inep. As provas do Enade são aplicadas, a cada ano, aos estudantes de diferentes grupos de áreas do conhecimento. Cada área do conhecimento é avaliada trienalmente. 
de famílias de baixa renda também cresceu no período estudado pelo autor, e ele ainda constata que o ensino privado e pago continua sendo majoritário no sistema de ensino superior brasileiro.

Os resultados da pesquisa de Ramos (2009), por sua vez, evidenciaram que o participante típico da mobilidade internacional nos cursos de graduação da UFMG pertencia à classe média, mas já se apresentava um crescimento inicial de participantes oriundos das classes populares, em função do apoio financeiro concedido pela instituição. A autora também constatou que os participantes dessa mobilidade eram estudantes que, ao longo da sua vida, construíram um "capital de mobilidade" e um currículo acadêmico de êxitos, comparativamente à média dos alunos da instituição estudada, a UFMG nesse caso.

Em 2010, o Fonaprace iniciou uma pesquisa encomendada pela Andifes com o objetivo de mapear a vida social, econômica e cultural dos estudantes de graduação presencial das universidades federais brasileiras. Com os resultados alcançados pelo perfil traçado, pretendia-se embasar a construção de ações de assistência estudantil e/ou qualificar as já existentes. Essa pesquisa revelou que quase a metade dos estudantes das Universidades Federais pertencia às classes populares e que eram oriundos de escolas públicas de ensino médio. A pesquisa mostrou também que, em todas as regiões do país, as mulheres eram o grupo predominante nessas instituições (percentual nacional de 53,5\%) e que a média de idade desses estudantes era de 23 anos. A representação dos povos indígenas nas universidades tinha diminuído, e o percentual de estudantes da raça/cor/etnia preta tinha aumentado. Mais de um terço dos estudantes pesquisados trabalhava, e também foi considerado notável o percentual de estudantes envolvidos em ações acadêmicas de ensino, pesquisa e extensão. A maioria desses estudantes eram filhos de pais que possuíam, pelo menos, o ensino médio completo. O estudo também apontou que o bom domínio da língua inglesa é característico das classes altas em contraste com as classes populares. E, por fim, dentre os fatores que afetam o desempenho acadêmico, foram destacadas, pelos estudantes (43\%), as dificuldades de adequação às novas situações, envolvendo adaptação à cidade, à moradia ou à separação das famílias.

\section{Caracterização sociodemográfica}

Demografia é uma área da ciência geográfica voltada para o estudo da população. Um perfil sociodemográfico pretende obter e analisar as características de determinado grupo social a partir de variáveis, como: gênero, idade, escolaridade, renda, raça, tipo de ocupação, 
dentre outras. Para este trabalho, foram eleitas algumas daquelas variáveis utilizadas pelas pesquisas de perfis educacionais de Ramos (2009) e Ristoff (2013) e pelo Fonaprace (2011): sexo, idade, raça, número de irmãos, nível de escolaridade dos pais e a renda declarada.

Dentre os 575 questionários enviados aos participantes do PAMA nas instituições signatárias, entre os anos de 2011 a 2013, 207 (36\%) foram respondidos. A distribuição espacial dos respondentes foi bastante significativa. Foram obtidas respostas de participantes localizados em 24 das 27 unidades federativas do Brasil, sendo: 12\% da Região Nordeste, 9\% da Região Norte, 18\% da Região Sul, 14\% da Região Centro-Oeste e 46\% da Região Sudeste. Nesta última região, com destaque para o estado de Minas Gerais, se encontra o maior número de IFES signatárias do PAMA e, consequentemente, o de respondentes do questionário (51) veio de Minas Gerais, coincidindo com o fato de ser aí que se encontra a maior quantidade de estudantes participantes dessa política. Apenas Sergipe, Piauí e Acre não estão representados entre as respostas obtidas.

No que diz respeito à idade, segundo os dados aglutinados através do instrumento de pesquisa, o mais velho, dentre os participantes respondentes, nasceu em 1968, e o mais novo, em 1995, sendo que a maioria está situada na faixa etária de 22 a 26 anos. Ressalta-se que a idade considerada ideal para cursar o ensino superior é de 18 a 24 anos. Conforme mostra a Tabela 1, a qual se refere ao sexo dos participantes do PAMA respondentes do questionário, as estudantes do sexo feminino tiveram maior participação no Programa, no período deste estudo.

Tabela 1 - Número de respondentes por sexo

\begin{tabular}{ccc}
\hline Sexo & Número de respostas & \% \\
\hline Feminino & 120 & 58 \\
Masculino & 87 & 42 \\
\hline Total & $\mathbf{2 0 7}$ & $\mathbf{1 0 0}$ \\
\hline
\end{tabular}

Fonte: Respostas ao instrumento de pesquisa. Elaboração da autora (2014).

Nos últimos anos, a predominância de estudantes do sexo feminino nas escolas vem ocorrendo em todos os níveis de ensino, no Brasil. Um estudo do Inep, realizado por Ristoff et al. (2007), aponta que, naquele ano, as mulheres eram maioria nas escolas brasileiras, a partir da $5^{\mathrm{a}}$ série do ensino fundamental, mesmo os homens sendo maioria na sociedade, até os 20 anos de idade. O Censo da Educação Superior de 2010 mostra, igualmente, que as mulheres têm maior taxa de ingresso e representatividade no ensino superior, além de terem as maiores taxas de conclusão dos cursos universitários. 
Segundo Rosemberg (2001), as mulheres têm uma progressão escolar um pouco mais regular que a dos homens. Em geral, os homens possuem um número maior de interrupções em suas trajetórias escolares, como, por exemplo, as causadas pelas reprovações. E, talvez, esse seja um dos fatores que explicam a permanência das mulheres na escola, durante um período maior do que o dos homens, servindo ainda como causa para que elas sejam maioria no ensino superior.

A definição de raça é bastante discutida e, para um estudo mais aprofundado sobre a temática, recomenda-se a leitura de Guimarães (2003). Contudo, para apreender os aspectos relativos à composição étnico-racial dos estudantes do PAMA, utilizou-se da seguinte pergunta: "Como você se considera?". As respostas estão agrupadas na Tabela 2, demonstrando que a maioria $(63 \%)$ se considera branco.

Tabela 2 - Número de respondentes por cor

\begin{tabular}{ccc}
\hline Cor & Número de respostas & $\mathbf{\%}$ \\
\hline Amarelo & 2 & 1 \\
Branco & 130 & 63 \\
Indígena & 5 & 2 \\
Negro & 14 & 7 \\
Pardo & 56 & 27 \\
\hline Total & $\mathbf{2 0 7}$ & $\mathbf{1 0 0}$ \\
\hline
\end{tabular}

Fonte: Respostas ao instrumento de pesquisa. Elaboração da autora (2014).

O estudo de Ristoff (2013) mostra que o perfil dos estudantes de graduação brasileiros é composto majoritariamente por brancos. Os cursos de alta demanda no processo seletivo das universidades, a Medicina, por exemplo, possui o maior percentual de brancos, e os cursos de licenciatura predominam entre os cursos com o menor percentual de brancos.

Conforme Munanga (2003), antes das políticas de inclusão e das diferentes modalidades de ações afirmativas hoje existentes, o número de estudantes negros no nível de ensino superior era menor que $2 \%$.

No Censo de 2010, do IBGE (Instituto Brasileiro de Geografia Estatística), os indivíduos pretos e pardos constituíam o grupo majoritário da população brasileira, contrastando-se com o perfil dos participantes do PAMA, que são majoritariamente brancos, conforme apontado por esta pesquisa.

A faixa de renda mensal familiar declarada pelos respondentes participantes do Programa pode ser verificada na Tabela 3. 
Tabela 3 - Renda mensal familiar dos respondentes

\begin{tabular}{ccc}
\hline Faixa de renda & Número de respostas & \% \\
\hline Até 3 salários mínimos & 62 & 30 \\
De 3 a 10 salários mínimos & 100 & 48 \\
De 10 a 30 salários mínimos & 44 & 21 \\
Acima de 30 salários & 1 & 1 \\
\hline Total & $\mathbf{2 0 7}$ & $\mathbf{1 0 0}$ \\
\hline
\end{tabular}

Fonte: Respostas ao instrumento de pesquisa. Elaboração da autora (2014).

Ressalta-se que a variável renda sempre pode apresentar fragilidades, pois a resposta pode não refletir a realidade, uma vez que é declarada pelos estudantes. O estudo de Alves e Soares (2009) relatou que, quando a pergunta sobre a renda familiar não é respondida pelos pais, a frequência de respostas inválidas costuma ser elevada. De todo modo, foi possível verificar a presença de uma diversidade na condição econômica dos participantes, estando $78 \%$ deles na faixa de até 10 salários mínimos. Como todos os respondentes fizeram uso da bolsa Andifes/Santander, mesmo não tendo sido esse um parâmetro utilizado pelas IFES para selecionar os discentes para o Programa, a grande maioria desse grupo situa-se nas faixas de renda baixa e média.

A renda familiar da maioria dos participantes do PAMA está compreendida na faixa de 3 a 10 salários mínimos. De acordo com os dados da Pesquisa Nacional por Amostra de Domicílios (Pnad), realizada pelo IBGE, em 2011, o grupo de famílias na faixa de renda de até 3 salários mínimos corresponde a $52 \%$ das famílias brasileiras. Por volta de $34 \%$ dos estudantes de graduação brasileiros estão na faixa de renda mensal familiar de até três salários mínimos, e, especificamente no PAMA, eles são 30\%, conforme exemplificado no Gráfico 1. 
Gráfico 1 - Percentual de pessoas com renda familiar de até três salários mínimos na sociedade brasileira, na graduação do ensino superior e no PAMA

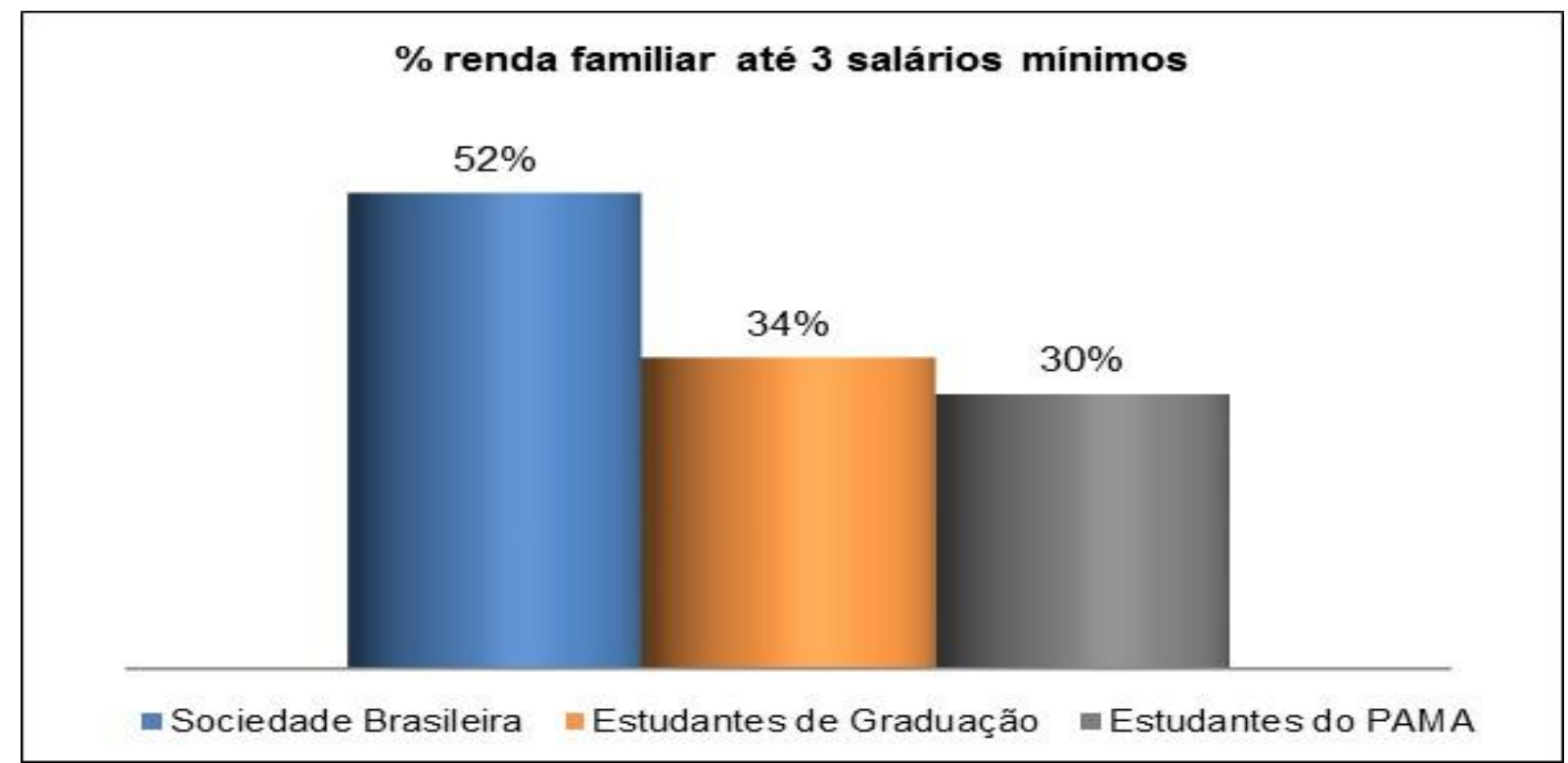

Fonte: IBGE, PNAD e respostas ao instrumento de pesquisa. Elaboração da autora (2014).

A predominância de estudantes pertencentes à classe média no Programa demonstra que essa camada social tende a investir mais nas oportunidades educacionais, para uma formação acadêmica diferenciada. A participação de estudantes de alta renda (acima de 30 salários mínimos) no PAMA é pequena, como mostra o Gráfico 2.

Gráfico 2 - Percentual de pessoas com renda familiar de mais de 10 salários mínimos na sociedade brasileira, na graduação do ensino superior e no PAMA

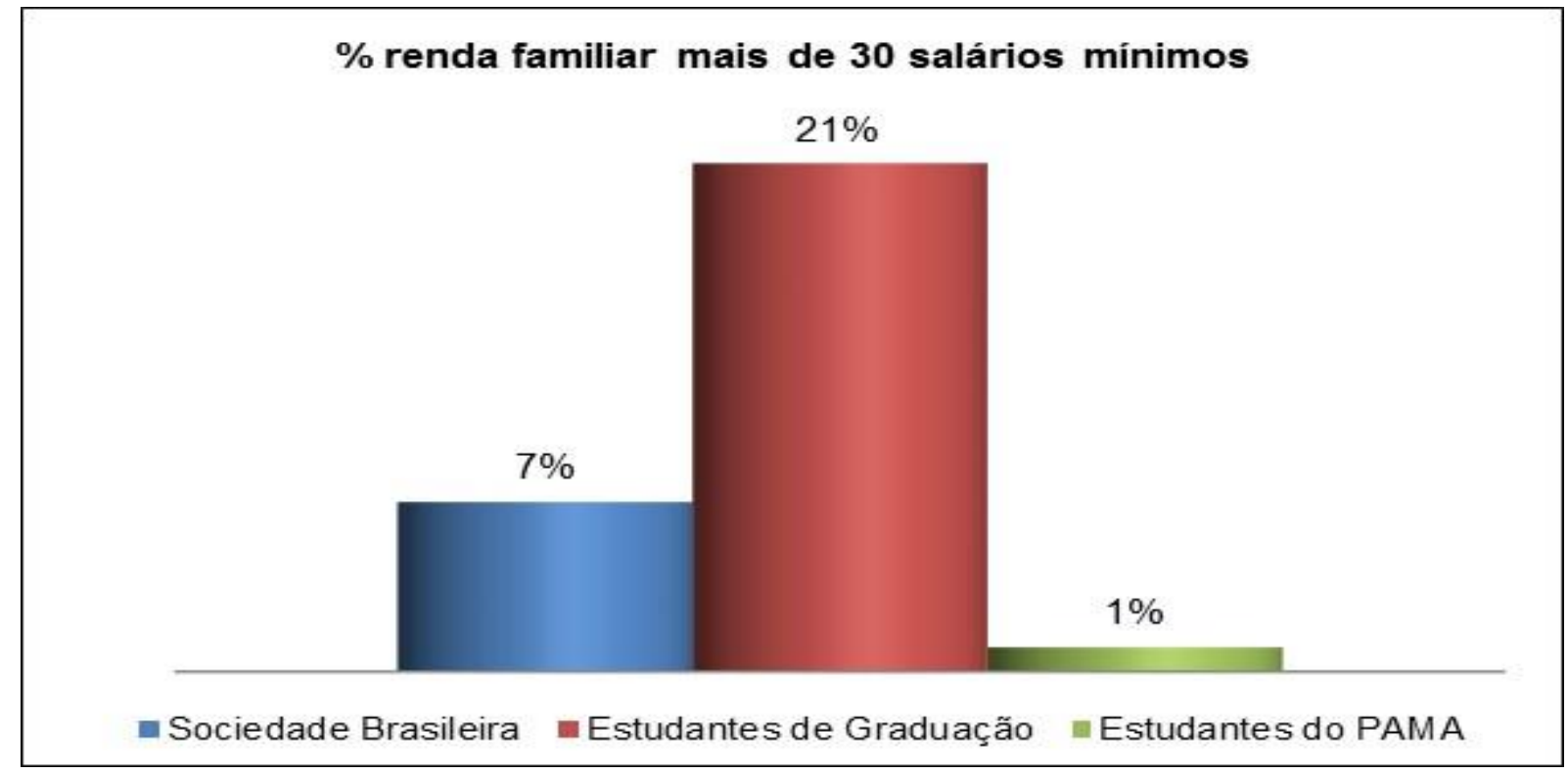

Fonte: IBGE, PNAD e Respostas ao instrumento de pesquisa. Elaboração da autora (2014). 
Isso pode ser atribuído a dois fatores: provavelmente, os discentes com maior renda participam mais ativamente de intercâmbios e de mobilidades internacionais; ou, conforme Nogueira (2002), a elite nem sempre está preocupada com o valor do seu diploma no mercado acadêmico, ou com uma escolarização com diferentes capitais simbólicos agregados ${ }^{2}$, por vezes, apenas a obtenção do diploma já atende seu interesse com a escola. A autora ainda demonstrou que as elites econômicas, no que diz respeito às mobilidades estudantis internacionais, costumam preferir estadias de curta duração no exterior, em especial em cursos de idiomas, evitando, assim, processos de seleção e as restrições dos editais dos programas de mobilidade.

Portanto, cabe notar que pode haver uma correlação entre os níveis de renda dos estudantes e a mobilidade acadêmica que procuram. Mesmo porque os capitais envolvidos na mobilidade, tanto os econômicos (custo de vida em outro local, ou em outro país) quanto os culturais (domínio de outra língua, por exemplo), são diferentes. Tais diferenças acabam delimitando as oportunidades de escolha dos estudantes interessados em participar de um programa de mobilidade acadêmica. Porém, este estudo não consegue precisar quantos estudantes não se candidatam ao PAMA por restrições econômicas, por não ser esse seu objetivo.

O número de irmãos é importante para uma análise conjunta com a renda mensal familiar. Dados demonstram que o número de filhos por mulher vem sendo reduzido no Brasil, desde a década de 1960, e, segundo o Censo (IBGE, 2010), as mulheres têm, em média, 1,9 filhos. Os dados sobre os participantes do PAMA estão de acordo com esse resultado, uma vez que a maior parte deles possui apenas um irmão, ou seja, provém de famílias pouco numerosas, conforme dados da Tabela 4.

2 O capital pode ser definido como um conjunto de bens acumulados que são produzidos, distribuídos, consumidos, investidos e perdidos nas lutas simbólicas ocorridas nos campos sociais. O capital de mobilidade, então, seria um tipo de capital simbólico agregado ao diploma, permitindo uma diferenciação positiva para a disputa no campo acadêmico e, quiçá, no campo de trabalho. 
Tabela 4 - Número de respondentes por quantidade de irmãos

\begin{tabular}{ccc}
\hline Quantidade de irmãos & Número de respostas & $\mathbf{\%}$ \\
\hline Nenhum & 20 & 10 \\
Um & 81 & 39 \\
Dois & 68 & 33 \\
Três ou mais & 38 & 18 \\
\hline Total & $\mathbf{2 0 7}$ & $\mathbf{1 0 0}$ \\
\hline
\end{tabular}

Fonte: Respostas ao instrumento de pesquisa. Elaboração da autora (2014).

Dentre os que possuem três ou mais irmãos, metade tem renda de até três salários mínimos, e, dentre os que possuem um irmão, 64\% possuem renda entre 3 e 10 salários mínimos. A redução no número de filhos nas camadas médias da sociedade também pode ser considerada uma estratégia educativa, pois impede a diluição de recursos e permite investir mais na educação deles.

\section{Considerações sobre as trajetórias escolares}

Entende-se por trajetória escolar os "percursos diferenciados que os indivíduos ou grupos de indivíduos realizam no interior dos sistemas de ensino" (NOGUEIRA; FORTES, 2004, p. 59). Essa trajetória, embora específica ao campo escolar, é condicionada por fatores extraescolares, sobretudo a origem social dos estudantes. Segundo Bourdieu (2003), é principalmente o capital cultural, na sua forma incorporada, caracterizada pelo modo de pensar e agir, pelo gosto e um bom gosto, pela desenvoltura e boa retórica, herdado por aqueles estudantes pertencentes às classes cultas e cultivadas, que marca positivamente a trajetória escolar deles, transformando herança social e cultural em mérito escolar.

Embora se reconheça a noção de disposições, proposta por Lahire (2004), na qual o indivíduo contemporâneo, mesmo pertencente às camadas populares, com influência de vários meios (familiares, amigos, escola, igreja, vizinhança), incorpora diferentes gostos e modos de pensar e agir, as diferentes disposições de um indivíduo podem, ou não, ajudá-lo a romper com o ciclo de reprodução do capital cultural incorporado de sua classe social de origem e a alcançar, por exemplo, o sucesso escolar.

Para as observações acerca das trajetórias escolares dos participantes desta pesquisa, as variáveis consideradas foram: o tipo de estabelecimento no qual o ensino médio foi realizado, a idade com a qual foram admitidos no ensino superior, o turno da graduação e as atividades remuneradas desempenhadas durante o ensino superior. 
Para Braga e Peixoto (2006), o tipo de escola frequentada no ensino médio (pública ou privada) é uma variável importante para descrever o perfil dos estudantes do ensino superior, porque é uma boa medida da condição socioeconômica de suas famílias. Dessa forma, com o intuito de obter a origem escolar dos pesquisados, uma das perguntas feitas foi: "Onde você cursou o ensino médio?”. A Tabela 5 mostra as repostas agrupadas nas cinco opções oferecidas: todo em escola pública, todo em escola privada (particular), maior parte em escola pública, maior parte em escola privada (particular), metade em escola pública e metade em escola privada (particular).

\section{Tabela 5 - Número de respondentes por tipo de escola frequentada no ensino médio}

\begin{tabular}{ccc}
\hline Tipo de escola & Número de respostas & \% \\
\hline Todo em escola pública & 86 & 41 \\
Todo em escola privada (particular) & 100 & 48 \\
Maior parte em escola pública & 6 & 3 \\
Maior parte em escola privada (particular) & 12 & 6 \\
Metade em escola pública e metade em escola privada \\
(particular)
\end{tabular}

Fonte: Respostas ao instrumento de pesquisa. Elaboração da autora (2014).

Sabe-se, entretanto, que os cursos de ensino médio no país - diurnos, noturnos, profissionalizantes - e a natureza administrativa das instituições - públicas ou privadas -, dentre outros aspectos, implicam em diferenças significativas que não são alcançadas por essa pergunta.

Verifica-se, na maior parte dos sujeitos desta pesquisa, uma trajetória escolar sem interrupções, dado que metade deles (51\%) iniciou um curso de graduação com 17 ou 18 anos (Tabela 6). 
Tabela 6 - Número de respondentes por idade de entrada no ensino superior

\begin{tabular}{ccc}
\hline Idade & Número de respostas & \% \\
\hline 17 ou 18 anos & 105 & 51 \\
19 ou 20 anos & 70 & 34 \\
21 ou 22 anos & 11 & 5 \\
23 ou 24 anos & 12 & 6 \\
Acima de 24 anos & 9 & 4 \\
\hline Total & $\mathbf{2 0 7}$ & $\mathbf{1 0 0}$ \\
\hline
\end{tabular}

Fonte: Respostas ao instrumento de pesquisa. Elaboração da autora (2014).

Considera-se que, possivelmente, esses estudantes tiveram um percurso escolar regular, sem reprovações ou outros tipos de interrupções dos estudos. A idade com a qual os estudantes adentram no ensino superior nos dá pistas sobre os bons resultados obtidos por eles ao longo de suas trajetórias escolares, o que permite conjecturar a linearidade desse percurso.

É interessante verificar que, dentre os 105 estudantes que adentraram no ensino superior com 17 ou 18 anos, 48 cursaram o ensino médio todo em escola privada, e, dos 70 que entraram no ensino superior com 19 ou 20 anos, 45 cursaram também o ensino médio todo em escola privada. Já dos 9 que iniciaram um curso de graduação de ensino superior com mais de 24 anos, todos cursaram o ensino médio em escola pública e cursam, ou cursaram, cursos das áreas de humanas ou de ciências sociais aplicadas.

Dentre os dados apresentados por Ristoff (2013), em seu estudo, está a constatação de que aproximadamente $44 \%$ dos estudantes de graduação não trabalham e têm seus gastos financiados por suas famílias. São, portanto, $56 \%$ os estudantes brasileiros de ensino superior que trabalham e estudam. Há também um alto percentual de estudantes trabalhadores nos cursos de licenciatura. Sobre a presença de estudantes de outras áreas que trabalham, como as engenharias, o autor pondera que isso pode estar associado à busca de oportunidades precoces de experiência profissional e não unicamente à necessidade econômica. Ao comparar esses dados com os dos sujeitos participantes do PAMA desta pesquisa, observa-se que o exercício de atividade remunerada durante a graduação é considerável. Contudo, a remuneração das atividades realizadas por eles é, na maioria dos casos, apenas um complemento ao apoio financeiro disponibilizado pelas famílias para garantir a escolarização de ensino superior de seus filhos.

Conforme a Tabela 7, a maior parte dos participantes respondentes (41\%) não trabalha, e os gastos são financiados pela família, e outra parte $(38 \%)$ trabalha, mas recebe ajuda financeira da família. 
Tabela 7 - Relação trabalho, renda e estudo dos respondentes

\begin{tabular}{ccc}
\hline Situação vivenciada durante a graduação & Número de respostas & \% \\
\hline Não trabalham, e os gastos são financiados pela família & 86 & 41 \\
Trabalham e contribuem com o sustento da família & 11 & 6 \\
Trabalham e sustentam-se & 30 & 14 \\
Trabalham e recebem ajuda da família & 79 & 38 \\
Trabalham e são os principais responsáveis pelo sustento da família & $\mathbf{2 0 7}$ & $\mathbf{1 0 0}$ \\
\hline Total & & 1 \\
\hline
\end{tabular}

Fonte: Respostas ao instrumento de pesquisa. Elaboração da autora (2014).

Deve-se, contudo, explicar que o que muitos deles consideraram trabalho configura-se, mais especificamente, como atividade acadêmica remunerada através de bolsas diversas relativas às ações de ensino, pesquisa e/ou extensão desenvolvidas por eles. Entre os 79 pesquisados que disseram trabalhar e receber ajuda da família, 71 são bolsistas. As bolsas recebidas, conforme declarado, são de programas de iniciação científica, de programas de monitoria, de estágios remunerados, de ações de extensão, de assistência estudantil, do Programa de Educação pelo Trabalho para a Saúde (PET-Saúde), do Programa Institucional de Bolsas de Iniciação à Docência (Pibid), do Programa de Educação Tutorial (PET), dentre outras. De acordo com os dados desta pesquisa, a concentração de estudantes que trabalhavam e que participaram do PAMA é menor nos cursos das áreas: Ciências da Saúde, Engenharias e Ciências Agrárias.

Dentre os $41 \%$ que não trabalham e são completamente financiados pela família, a renda declarada da maioria das famílias está entre 3 a 10 salários mínimos. Dentre os $14 \%$ que trabalham e se sustentam, mais da metade possuem renda de até 3 salários mínimos e estão vinculados a cursos das áreas de Ciências Humanas e de Ciências Sociais Aplicadas, os quais, em sua grande parte, são do período noturno.

No que diz respeito à escolaridade dos pais em relação aos cursos de graduação, Ristoff (2013) afirma haver forte correlação entre renda familiar, origem escolar, cor, trabalho e escolaridade dos pais.

Percebe-se, por exemplo, que os cursos identificados como os mais brancos, com estudantes mais ricos, que não trabalham e que vêm da escola privada de ensino médio, são também em sua maioria de estudantes que vêm de famílias cujos pais têm escolaridade superior (RISTOFF, 2013, p. 18).

O capital cultural dos pais constitui um importante fator para o êxito escolar dos filhos (BOURDIEU, 2003). Entende-se, assim, que a escolaridade é um dos fatores determinantes da renda obtida pelas famílias. No PAMA, observa-se que a escolaridade dos pais dos 
respondentes está concentrada no nível de ensino médio e no nível de ensino superior, conforme apresentado na Tabela 8.

\section{Tabela 8 - Escolaridade dos pais dos respondentes}

\begin{tabular}{|c|c|c|c|c|}
\hline Nível de escolaridade final & $\begin{array}{l}\text { Escolaridade do pai/ } \\
\text { Número de respostas }\end{array}$ & $\%$ & $\begin{array}{l}\text { Escolaridade da mãe/ } \\
\text { Número de respostas }\end{array}$ & $\%$ \\
\hline Nenhuma escolaridade & 7 & 3 & 1 & 1 \\
\hline $\begin{array}{l}\text { Ensino fundamental: de } 1^{\mathrm{a}} \mathrm{a} \\
4^{\mathrm{a}} \text { série }\end{array}$ & 20 & 10 & 20 & 10 \\
\hline $\begin{array}{l}\text { Ensino fundamental: de } 5^{\mathrm{a}} \text { a } \\
8^{\mathrm{a}} \text { série }\end{array}$ & 29 & 14 & 21 & 11 \\
\hline Ensino médio & 77 & 37 & 77 & 37 \\
\hline Ensino superior & 74 & 36 & 84 & 41 \\
\hline Total & 207 & 100 & 207 & 100 \\
\hline
\end{tabular}

Fonte: Respostas ao instrumento de pesquisa. Elaboração da autora (2014).

Ao fazer uma correlação entre a escolaridade dos pais com a renda familiar dos respondentes participantes do PAMA, constata-se que, dentre os que possuem pai ou mãe sem escolaridade alguma, a renda de suas famílias está concentrada na faixa de até 3 salários mínimos. Dentre os que possuem pai ou mãe com escolaridade de ensino fundamental, a renda de suas famílias, na maior parte dos casos, também é de até 3 salários mínimos. Já quando se considera a escolaridade de ensino médio ou superior, a renda da maior parte das famílias dos respondentes situa-se na faixa de 3 a 10 salários mínimos. Logo, os participantes do PAMA são, em sua grande parte, oriundos de famílias com pais escolarizados, com ensino médio ou superior completo e com renda média mensal de 3 a 10 salários mínimos.

A maior parte dos pesquisados são estudantes que têm seus custos totalmente ou apenas parcialmente financiados pelos pais. Esse último caso deve-se pelo fato de os estudantes desempenharem atividades acadêmicas remuneradas ou obterem suporte financeiro de políticas de assistência estudantil e, possivelmente, enxergarem a escolarização como uma possibilidade de ascenderem socialmente.

Com relação ao fluxo de estudantes entre as instituições participantes do PAMA, a Universidade Federal do Espírito Santo, a Universidade de Brasília e a Universidade Federal Fluminense foram as que mais enviaram discentes para outras instituições signatárias do convênio. Já dentre as três instituições mais escolhidas como destino pelos pesquisados, estão a Universidade Federal do Rio Grande do Sul, a Universidade do Rio de Janeiro e a Universidade de Santa Catarina. Contudo, essa aglutinação em três IFES é apenas conjuntural, pois os pesquisados eram provenientes de IFES diversas e foram para IFES diferentes. 
Acredita-se que, apenas com as respostas obtidas por este instrumento de pesquisa (o questionário), não é possível aferir se essa escolha está relacionada com fatores como o prestígio das instituições, por exemplo.

Considerando os cursos de origem do público participante do PAMA, eles provêm, em sua maioria, da área de Ciências Sociais Aplicadas. Os sujeitos pesquisados são provenientes de cursos diversos, havendo estudantes de todas as áreas do conhecimento com participação pontual no PAMA. Apenas nas áreas: Ciências Sociais e Aplicadas, Linguística, Letras e Artes e Ciências Humanas, pode-se perceber um fluxo de participação maior, especificamente nos cursos de Comunicação Social, Letras e Sociologia.

Quanto ao turno dos cursos de graduação frequentados pelos participantes do PAMA, os dados mostram que 155 (três quartos), dos 207 respondentes, são de cursos diurnos, e 52, apenas um quarto, são de cursos noturnos. O que indica que a participação em programas de mobilidade acadêmica é também condicionada pela disponibilidade do discente de se dedicar integralmente ao estudo ou de ter que dividir seu tempo de estudo com a realização de outras atividades. Como complemento, acrescenta-se que, no perfil socioeconômico e cultural dos estudantes de graduação das universidades federais brasileiras (2011), os estudantes das classes populares predominam nos cursos do período noturno e que os estudantes das classes altas predominam nos cursos diurnos.

\section{Avaliações sobre a experiência vivida no PAMA}

Para que os participantes avaliassem a vivência da mobilidade, foram-lhes apresentados os seguintes aspectos: aprendizado acadêmico, aproveitamento de créditos, divulgação, experiência da mobilidade acadêmica, informações sobre o programa na comunidade acadêmica, número de bolsas financiadas, interação entre as instituições de ensino superior, recepção na instituição de destino, vivência em outro lugar, e os respondentes puderam expressar se consideravam positivamente ou negativamente cada aspecto.

Apenas 3 respondentes, dentre os 207, avaliaram negativamente o aprendizado acadêmico obtido durante a mobilidade. Já o aproveitamento no histórico escolar de créditos cursados durante a mobilidade acadêmica foi considerado fator negativo para 30 deles. Mas, a experiência propiciada pela migração acadêmica temporária foi considerada positiva por quase a totalidade dos respondentes (199).

Mais da metade dos sujeitos (119) avaliaram que a divulgação do PAMA é ruim, e $51 \%$ acharam que as informações sobre o Programa, na comunidade acadêmica, são 
ineficientes e também afirmaram que a interação entre as IFES no PAMA é boa. Apenas 40 deles tiveram impressão negativa da recepção que obtiveram na IFES de destino.

Uma parcela considerável dos respondentes (120) avaliou que o valor das bolsas financiadas pelo Convênio Andifes/Santander era adequado.

Apenas dois deles não recomendariam a participação no PAMA a outro colega. A justificativa apresentada para a não recomendação está relacionada à insatisfação deles com os procedimentos necessários que devem realizar junto ao controle acadêmico das IFES, para viabilizar a mobilidade acadêmica tanto na instituição de origem quanto na instituição de destino, conforme os dois relatos dos respondentes participantes desta pesquisa aqui transcritos:

\footnotetext{
Alguns pontos graves sobre a mobilidade acadêmica é que o aproveitamento de disciplinas é olhado antes com (o)a coordenador( $a$ ) da instituição de origem, para quando o aluno voltar a ter o máximo de aproveitamento possível. Isso foi feito no meu caso, mas além de não serem muitas disciplinas conseguidas, pois a ementa costuma não bater, ao retornar pra a instituição de origem, poucas disciplinas puderam ser aproveitadas, ou seja, o que foi olhado antes de ir e que seria aproveitado não foi.

A mobilidade acadêmica nacional contribui para a formação do profissional, resulta no processo de amadurecimento do discente. No entanto, os alunos não possuem orientação adequada para usufruir de todas as possibilidades que a graduação nas universidades públicas oferece.
}

Ao perguntar aos pesquisados se eles "gostariam de avaliar mais alguma coisa", as respostas foram basicamente, não. Alguns reclamaram sobre a falta de informação e de pessoas nas IFES com mais capacitação para darem as informações necessárias sobre o PAMA.

\section{Considerações finais}

A mobilidade é uma prática estudantil que sempre foi um elemento importante na formação escolar do estudante de ensino superior e que também é um fator-chave para o seu crescimento. Entretanto, assim como a mobilidade não é algo simples para os sujeitos, tampouco o é para as instituições de ensino superior. A maioria das IFES do Brasil ainda não desenvolveram sua estrutura física, seus sistemas acadêmicos, sua assistência estudantil e seu corpo técnico-administrativo para atender à mobilidade acadêmica estudantil.

Os estudos sobre a mobilidade acadêmica no Brasil vêm aumentando, mas a maior parte dos autores se concentra nas modalidades que ocorrem entre o país e o exterior, na internacionalização da educação, na cooperação interinstitucional, e quase nunca nas migrações acadêmicas que ocorrem dentro do próprio país. No presente estudo, procurou-se compreender o perfil dos participantes de uma mobilidade acadêmica brasileira, pois o Brasil 
é um país de dimensão continental, em evidente crescimento econômico e, após viver um aumento da rede privada de ensino superior, especialmente na década de 90, vivenciou, recentemente, uma política de crescimento e interiorização da sua rede federal de ensino. É nesse contexto que a Andifes concebeu o Programa Andifes de Mobilidade Acadêmica. Ele é fruto da cooperação interinstitucional para promover a mobilidade acadêmica estudantil no país e estabelece novas experiências e outras vivências nas IFES e entre elas.

O PAMA ainda é um programa com pouca participação, mas possui potencial para crescer e se tornar uma experiência relevante para a formação de ensino superior, no país. Ele permite a interação das identidades regionais dos cursos de graduação, e essa interação é um benefício para o desenvolvimento do conhecimento do e no Brasil. Um programa de mobilidade acadêmica interna promove o fortalecimento político e cultural do país e o desenvolvimento e consolidação de uma identidade de formação no ensino superior brasileiro.

A análise dos dados mostrou que os estudantes participantes do PAMA são, majoritariamente, brancos, do sexo feminino, com média de idade de 23 anos, provenientes de famílias pequenas (com poucos irmãos) e de pais com escolaridade de ensino médio, ou de ensino superior, e com faixa de renda situada entre 3 e 10 salários mínimos. São, na grande maioria, discentes de cursos de graduação diurnos, da área de Ciências Sociais e Aplicadas, de universidades localizadas na região Sudeste, tendo percursos escolares sem grandes interrupções.

Mesmo existindo um convênio de regulação do Programa, verificou-se que ele foi recontextualizado no interior das universidades. Isso foi observado nos casos de participantes que extrapolaram o tempo máximo de mobilidade estipulado, assim como nos relatos de participantes que aderiram a ele exclusivamente para resolver questões pessoais e não para fins acadêmicos. Além disso, constatou-se haver falta de conhecimento sobre o Programa e desencontros nas informações existentes.

O convênio do programa não estabelece, como objetivo, a necessidade de compartilhamento da experiência individual para um plano mais coletivo após a mobilidade, etapa importante para a troca de experiências entre os alunos que participaram de programas de mobilidade acadêmica com os demais interessados em deles participar, o mesmo ocorrendo em relação àqueles que sequer têm conhecimento dessa possibilidade. Ampliação dos meios de comunicação e de informações virtuais, aos quais os jovens estão bastante conectados, ajudaria na visibilidade e garantiria maior padronização das informações.

A escolha estudantil pela IFES na qual será realizada a mobilidade acadêmica é influenciada por aspectos como: a volta para a cidade de origem, o retorno para a casa da 
família, a otimização dos gastos, a possibilidade de realização de estágios, o estabelecimento de contatos para prosseguir na universidade através de programas de pós-graduação, o mercado de trabalho futuro, a vivência em uma cidade de grande porte. Nesse sentido, a localização geográfica das universidades se tornou um fator relevante no fluxo da mobilidade discente. Deve ser ressaltado que a intenção da escolha da mobilidade acadêmica estudantil nacional, em lugar da internacional, possui outros dois determinantes: não há necessidade de domínio de língua estrangeira e o custo financeiro para participação nesse tipo de programa é geralmente inferior ao necessário para um deslocamento internacional.

A mobilidade acadêmica, tanto nacional quanto internacional, traz à tona a demanda pelo debate e o estabelecimento de processos de flexibilização curricular. Os colegiados de curso de graduação precisam colocar a mobilidade em pauta no processo de elaboração e/ou atualização dos projetos pedagógicos, não só porque ela se constitui numa demanda crescente nas instituições de ensino superior de todo o mundo, como porquê são evidentes as dificuldades encontradas pelos estudantes ao regressarem, para ajustar as atividades desenvolvidas fora da instituição de origem.

Acredita-se que o conhecimento produzido por esta pesquisa, conjuntamente com os demais que são realizados sobre os perfis dos estudantes de graduação do Brasil, pode contribuir para a realização de proposições, avaliações e análises embasadas para a construção de políticas educacionais adequadas ao sistema federal de ensino superior brasileiro, em especial daquelas que tangem as migrações acadêmicas temporárias.

\section{Referências}

ALVES, Maria Teresa; SOARES, José Francisco. Medidas de nível socioeconômico em pesquisas sociais: uma aplicação aos dados de uma pesquisa educacional. Opinião Pública, Campinas, v. 15, n. 1, p. 1-30, jun. 2009.

BOURDIEU, Pierre. O poder simbólico. Rio de Janeiro: Bertrand Brasil, 2003.

BRAGA, Mauro Mendes; PEIXOTO, Maria do Carmo de Lacerda. Censo Socioeconômico e étnico dos estudantes de graduação da UFMG. Belo Horizonte: Editora da UFMG, 2006.

FONAPRACE. Fórum Nacional de Pró-Reitores de Assuntos Comunitários e Estudantis. Perfil Socioeconômico e Cultural dos Estudantes de Graduação das Universidades Federais Brasileiras. Brasília, 2011. Disponível em: <http://www.andifes.org.br/wpcontent/files_flutter/1377182836Relatorio_do_perfi_dos_estudantes_nas_universidades_feder ais.pdf>. Acesso em: 01 jun. 2014.

GUIMARÃES, Antônio Sérgio Alfredo. Como trabalhar com "raça" em sociologia. Educação e Pesquisa, São Paulo, v. 29, n. 1, p. 93-107, jan./jun. 2003. 
IBGE. Instituto Brasileiro de Geografia Estatística. Sinopse do censo demográfico 2010. Brasília, 2011. Disponível em: <http://www.censo2010.ibge.gov.br/sinopse/>. Acesso em: 10 jun. 2014.

LAHIRE, Bernard. Retratos sociológicos, disposição e variações individuais. São Paulo: Artmed, 2004.

MUNANGA, Kabengele. Ação afirmativa em benefício da população negra. Universidade e Sociedade, Brasília, v. 1, n. 1, p. 46-52, 2003.

NOGUEIRA, Cláudio; FORTES, Maria de Fátima. A importância dos estudos sobre trajetórias escolares na sociologia da educação contemporânea. Paidéia, Belo Horizonte, p. 57-73, 2004.

NOGUEIRA, Maria Alice. Elites econômicas e escolarização: um estudo de trajetórias e estratégias escolares junto a um grupo de famílias de empresários de Minas Gerais. 195 f. Tese (Professor Titular) - Universidade Federal de Minas Gerais, Belo Horizonte, 2002.

RAMOS, Viviane. Perfil e motivações dos estudantes participantes do "programa de mobilidade discente internacional para a graduação" da UFMG. 137 f. Dissertação (Mestrado em Educação) - Faculdade de Educação, Universidade Federal de Minas Gerais, Belo Horizonte, 2009.

RISTOFF, Dilvo et al. (Org.). A mulher na educação superior brasileira. Brasília: Instituto Nacional de Pesquisas Educacionais Anísio Teixeira, 2007.

RISTOFF, Dilvo. Perfil Socioeconômico do estudante de graduação: uma análise de dois ciclos completos do Enade (2004 a 2009). Cadernos do GEA, Rio de Janeiro: FLACSO, GEA; UERJ, LPP, 2013.

ROSEMBERG, Fúlvia. Educação Formal: mulher e gênero no Brasil contemporâneo. Revista de Estudos Feministas, Florianópolis, v. 9, n. 2, p. 515-540, 2001.

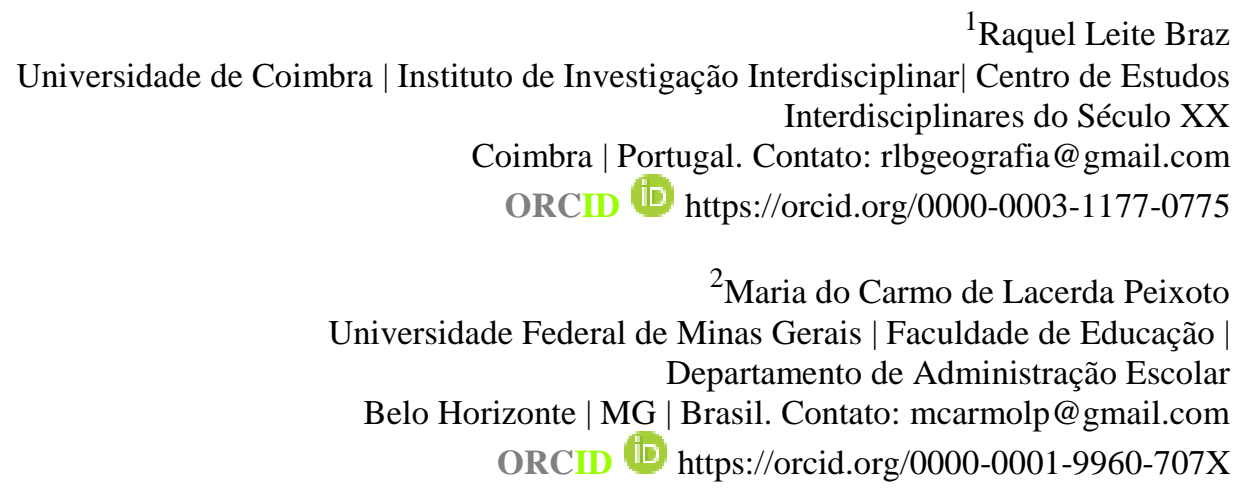

Artigo recebido em 25 de fevereiro de 2016 e aprovado em 12 de setembro de 2018. 